\title{
INTELIGÊNCIA COMPETITIVA COMO SUPORTE À ESTRATÉGIA EMPRESARIAL EM MICRO E PEQUENAS EMPRESAS: UM ESTUDO NA AEROTRÓPOLE DE BELO HORIZONTE
}

\section{RESUMO}

O contexto competitivo em que se insere uma empresa pode tornar-se ainda mais impactante quando há fatores ambientais que trazem grandes mudanças ao cenário. A implementação de uma Aerotrópole, que é uma estrutura urbana que tem como centro o aeroporto e, ao redor, atividades relacionadas a ele, demanda um posicionamento empreendedor e inovador das empresas, independentemente do seu porte. Com base em tal afirmativa, o foco deste artigo foi analisar como se configura a Inteligência Competitiva nas MPE da Aerotrópole de Belo Horizonte com vistas à elaboração de suas Estratégias Empresariais. Para alcançar o objetivo do estudo, foi realizada pesquisa do tipo descritiva, com abordagem qualitativa, via triangulação de fontes de coleta e análise de dados. Informalidade na implementação da Inteligência Competitiva e inabilidade na visualização de possibilidades de crescimento foram as características mais marcantes nos resultados obtidos. Há uma relevante oportunidade de melhoria nos processos de gestão das empresas pesquisadas, mostrando a importância da pesquisa realizada para o desenvolvimento econômico da região.

Palavras-chave: Micro e Pequenas Empresas; Inteligência Competitiva; Estratégia Empresarial; Competitividade; Aerotrópole de Belo Horizonte.

\section{COMPETITIVE INTELLIGENCE AS A SUPPORT TO THE BUSINESS STRATEGY IN MICRO AND SMALL COMPANIES: A STUDY IN THE AEROTROPOLIS OF BELO HORIZONTE}

\begin{abstract}
The competitive context in which an enterprise operates can become even more impacting when there are environmental factors that bring massive scenario changes. The implementation of an Aerotropolis, which is an urban structure that has the airport as its center and, in its surroundings, activities related to it, requires an entrepreneurial and innovative positioning of enterprises, regardless their size. Based on this statement, the focus of this article was to analyze how the Competitive Intelligence is configured in Micro and Small Companies at the Aerotropolis of Belo Horizonte with a view to the elaboration of its Business Strategies. To achieve the study purpose, a descriptive research was performed, using a qualitative approach, from the triangulation method to collection and analysis data. Informality in the implementation of Competitive Intelligence and a disability to view growth possibilities were the most striking features on the results. There is a significant opportunity for improvement in the management processes of the companies surveyed, showing the importance of research conducted for the economic development of the region.
\end{abstract}

Keywords: Small and Micro Enterprises; Competitive Intelligence; Business Strategy; Competitiveness; Belo Horizonte Aerotropolis. 
Inteligência Competitiva como Suporte à Estratégia Empresarial em Micro e Pequenas Empresas: Um Estudo na Aerotrópole de Belo Horizonte

\section{INTELIGENCIA COMPETITIVA COMO SOPORTE A LA ESTRATEGIA EMPRESARIAL EN MICRO Y PEQUEÑAS EMPRESAS: UN ESTUDIO EN LA AEROTRÓPOLIS DE BELO HORIZONTE}

\section{RESUMEN}

El contexto competitivo en que se inserta una empresa puede tornarse aún más impactante cuando hay factores ambientales que traen grandes cambios al escenario. La implementación de una Aerotrópolis, que es una estructura urbana que tiene como centro el aeropuerto y, alrededor, actividades relacionadas a él, demanda un posicionamiento emprendedor e innovador de las empresas, independientemente de su porte. Con base en esa afirmación, el foco de este artículo fue analizar cómo se configura la Inteligencia Competitiva en las MPE de la Aerotrópolis de Belo Horizonte mirando a la elaboración de sus Estrategias Empresariales. Para alcanzar el objetivo del estudio, se realizó una investigación de tipo descriptivo, con abordaje cualitativo, vía triangulación de fuentes de recolección y análisis de datos. La informalidad en la implementación de la Inteligencia Competitiva e inhabilidad en la visualización de posibilidades de crecimiento fueron las características más sobresalientes en los resultados obtenidos. Hay una relevante oportunidad de mejora en los procesos de gestión de las empresas encuestadas, mostrando la importancia de la investigación realizada para el desarrollo económico de la región.

Palabras chave: Micro y Pequeñas Empresas; Inteligencia Competitiva; Estrategia Empresarial; Competitividad; Aerotrópolis de Belo Horizonte.

\footnotetext{
${ }^{1}$ Doutor em Ciência da Informação pela Escola de Ciência da Informação da Universidade Federal de Minas Gerais UFMG. Professor do Mestrado Profissional em Administração da Fundação Pedro Leopoldo - FPL. Brasil. E-mail: professorfrederico@yahoo.com.br

${ }^{2}$ Doutora em Psicologia Social pela Universidade de Brasília - UnB. Professora da Fundação Pedro Leopoldo - FPL e da Pontifícia Universidade Católica de Minas Gerais - PUC/MG. Brasil. E-mail: esterjeunon@ @mail.com

${ }^{3}$ Mestre em Administração pela Fundação Pedro Leopoldo - FPL. Professora da Fundação Pedro Leopoldo - FPL. Brasil. E-mail: regianesantosbarbosa@gmail.com

${ }^{4}$ Mestranda em Administração pela Fundação Pedro Leopoldo - FPL. Brasil. E-mail: leonoracduarte@gmail.com
} 


\section{INTRODUÇÃ̃O}

A realidade que as empresas, de forma geral, enfrentam com o mercado globalizado, faz com que suas estratégias sejam definidas com foco na manutenção da capacidade competitiva, e isso exige que riscos sejam assumidos para que as demandas dos clientes sejam atendidas. As Micro e Pequenas Empresas (MPE) estão inseridas nesse contexto e precisam definir, para sua própria sobrevivência, o seu campo de atuação, o caminho que querem seguir e aonde querem chegar.

Acompanhar e interpretar o complexo ambiente empresarial é um desafio para estas empresas e, com práticas gerenciais sistematizadas, torna-se possível usar, estrategicamente, as inúmeras informações do meio externo para traçar ações que podem proporcionar sua sobrevivência. Tais práticas, advindas da Gestão da Informação e do Conhecimento (Choo, 2006) tornamse o alicerce para a implementação da Inteligência Competitiva (IC), que consiste em obter informações relevantes sobre fatos que ocorrem fora da empresa, de maneira a gerar futuros cursos de ação (Mafra Pereira, Carvalho \& Jordão, 2016). A Estratégia Empresarial embasada pela IC transforma-se em um elemento fundamental para que as MPE gerem valor superior aos concorrentes, diferenciando-se no disputado mercado (Alves, Antonialli, Lopes, Souki \& Reis Neto, 2013).

$\mathrm{O}$ contexto competitivo em que se insere uma empresa pode tornar-se ainda mais impactante quando há fatores ambientais que trazem grandes mudanças ao cenário, como, por exemplo, a implementação de uma Aerotrópole, que é uma estrutura urbana que tem como centro o aeroporto e, ao redor, em um raio de 30 quilômetros, atividades relacionadas a ele (Kasarda \& Lindsay, 2012). Em 2011, o Governo de Minas Gerais apresentou um novo projeto de ampliação do Aeroporto Internacional Tancredo Neves (Belo Horizonte - Confins, MG) e de seu entorno para os próximos 30 anos. Como noticiado pela mídia em nível nacional, o projeto, único na América do Sul, foi concebido visando fomentar a economia e também evitar o crescimento desordenado ao redor do citado Aeroporto (Maciel, 2014). Denominado como Aerotrópole de Belo Horizonte, o projeto apresentou uma lógica inovadora especialmente para o Aeroporto Internacional Tancredo Neves, principal instrumento da Aerotrópole e que tem uma localização privilegiada na região sudeste do país, onde se concentram $50 \%$ da população brasileira, $65 \%$ do Produto Interno Bruto (PIB) nacional e $65 \%$ da produção industrial (http://www.bh-airport.com.br, recuperado em 21, fevereiro, 2017).

A Aerotrópole de Belo Horizonte tem inspiração em modelos semelhantes e bem-sucedidos já implementados em vários países, como Holanda, Japão, Estados Unidos e Emirados Árabes. A proximidade das empresas ao modal aéreo garante ganhos de competitividade, de logística adequada para o escoamento da produção, favorecendo a atração de outros investimentos capazes de gerar empregos de qualidade, agregar valor à produção e introduzir inovação tecnológica. Para Belo Horizonte, há uma grande expectativa que tais fenômenos se repitam de forma semelhante (http://www.bh-airport.com.br, recuperado em 21, fevereiro, 2017). Há diversos investimentos previstos para os eixos aeroespacial e defesa, ciências da vida, tecnologia da informação e microeletrônico, além do turismo de negócios (Belissa, 2016). Já se instalaram, inclusive, lojas de grandes grupos comerciais na região.

Diante dos fatos descritos, é possível inferir que as MPE localizadas na área de influência da Aerotrópole de Belo Horizonte podem ser impactadas pelas mudanças desencadeadas pela nova dinâmica promovida. Kasarda e Lindsay (2012) afirmam que a Aerotrópole representa a lógica da globalização refletida em forma de cidade. Independentemente de ser considerado um fator positivo ou negativo, seus impactos são inevitáveis. Nesse sentido, as MPE precisam buscar melhora sua competitividade, principalmente por meio da inovação de negócios e empreendedorismo.

Para que se formem redes empresariais na Aerotrópole de Belo Horizonte, as empresas locais, especialmente as MPE, precisam desenvolver a capacidade de assimilar informações e aplicá-las eficazmente de maneira a criar valor. Levando-se em consideração esse cenário, a questão de pesquisa que se colocou para a realização deste trabalho foi: Como se configura a Inteligência Competitiva nas MPE da Aerotrópole de Belo Horizonte com vistas à elaboração de suas Estratégias Empresariais? Dessa forma, o objetivo geral deste trabalho foi analisar como se configura a Inteligência Competitiva nas MPE da Aerotrópole de Belo Horizonte com vistas à elaboração de suas Estratégias Empresariais, sendo a busca das respostas pautadas também pelos seguintes objetivos específicos: i) identificar as práticas de monitoramento do ambiente / Inteligência Competitiva realizadas pelas MPE da Aerotrópole de Belo Horizonte; ii) identificar como tais MPE planejam e implementam suas Estratégias Empresariais na Aerotrópole de Belo Horizonte e; iii) identificar o nível de percepção dessas MPE sobre a Aerotrópole de Belo Horizonte.

Com a proposta de um novo cenário social e econômico lançada com o projeto de ampliação do Aeroporto Internacional de Belo Horizonte - Confins (MG) e de seu entorno para os próximos 30 anos, as MPE instaladas nas cidades de Capim Branco, Confins, Matozinhos, Lagoa Santa, Pedro Leopoldo, São José da Lapa e Vespasiano encontram-se suscetíveis à influência do ambiente externo, e se constituíram, portanto, no contexto para a realização deste trabalho.

Destarte, esta pesquisa contribui, em termos teóricos para a Academia, como um estudo inédito ao 
analisar como se configura a IC nas MPE da Aerotrópole de Belo Horizonte com vistas à elaboração de suas Estratégias Empresariais. A pesquisa também proporciona reflexões e contribuições gerenciais sobre a atual gestão das organizações de pequeno porte localizadas nesta área de influência do Aeroporto, contribuindo com sugestões de melhorias não somente nas práticas de monitoramento do mercado e de IC, como também na sua contribuição para a elaboração de Estratégias Empresariais eficazes e eficientes.

Este artigo se apresenta organizado, primeiramente, por esta introdução, via apresentação do tema, a contextualização e a problematização da questão de pesquisa, e respectivos objetivos (geral e específicos) e justificativas. Em seguida, é apresentado o referencial teórico com o foco de enquadrar o problema da pesquisa do ponto de vista teórico. No terceiro capítulo são apresentados os procedimentos metodológicos utilizados, seguidos, no capítulo quatro, da apresentação e discussão dos resultados, com suas respectivas análises (organizadas conforme os objetivos específicos da pesquisa em confronto com a base teórica estudada). De forma conclusiva, são apresentadas as considerações finais do estudo, com os principais frutos e as limitações da pesquisa, assim como as possíveis contribuições de cunho acadêmico e prático.

\section{REFERENCIAL TEÓRICO}

A transformação do conhecimento por meio da organização dos dados e das informações constitui-se num processo fundamental para a definição e a implementação das estratégias organizacionais. Nesse sentido, o arcabouço que permite o enquadramento da pesquisa do ponto de vista teórico, viabilizando sua construção sólida e fundamentada, abordou, primeiramente e de forma independente, a Gestão da Informação e do Conhecimento no item 2.1., seguido do Monitoramento de Mercado e da Inteligência Competitiva (IC) no item 2.2., e finalizado com a Estratégia Empresarial em MPE no item 2.3.. Posteriormente, ao final deste capítulo de referencial teórico, tais alicerces conceituais foram alinhados no 'Modelo Teórico-Analítico: Competitividade para MPE', que se constitui no marco teórico do trabalho (item 2.4.), base da pesquisa ora realizada, e que subsidiou a coleta e a análise dos resultados obtidos.

\subsection{Gestão da Informação e do Conhecimento}

A competitividade encontra-se inserida em um mercado globalizado, no qual existe uma dinâmica criação de produtos e serviços e uma ferrenha disputa por clientes. O ambiente oferece, simultaneamente, oportunidades, mas apresenta desafios que precisam ser superados pelas organizações. "Acompanhar e interpretar o ambiente empresarial não é, certamente, tarefa fácil, devido às incessantes mudanças que se desenrolam nos ambientes de negócios contemporâneos" (Barbosa, 2006, p. 92).

Acontecimentos do ambiente externo à empresa devem ser interpretados para compreender situações e propor soluções. A informação é, portanto, vital à sustentabilidade e à competitividade das empresas e recebe influências do mercado globalizado, atrelado à Tecnologia da Informação, que desencadeia mudanças na gestão das empresas, uma vez que a facilidade de comunicação passa a ditar uma nova maneira de interagir com o ambiente externo (Hoffmann \& Chemalle, 2006).

Conquistar informações pertinentes requer competência: "atualmente, uma grande dificuldade existente nas organizações é a seleção conveniente das suas fontes de informação, tanto para os aspectos do negócio quanto para o dia a dia, para atender às suas necessidades" (Rocha Júnior, Guimarães \& Jeunon, 2014 , p. 248). Para tal, as organizações precisam administrar o conteúdo informacional através da Gestão da Informação e do Conhecimento (GIC). Através de práticas gerenciais sistematizadas, torna-se possível usar, estrategicamente, as inúmeras informações do meio externo para traçar ações que podem proporcionar não só a sobrevivência, mas também o crescimento da empresa (Albano \& Araújo, 2013).

Para captar sinais do ambiente externo, tanto do macroambiente quanto do microambiente, a organização deve coletar dados e interpretar informações para gerar conhecimento, de maneira sistemática. Caso contrário, não haverá sinergia com o competitivo mercado e tampouco elementos para a tomada de decisões (Barbalho, Valentim \& Hoffmann, 2007).

O primeiro conceito para a aplicabilidade da GIC a ser compreendido é o de dado, que é a matériaprima do processo. Segundo Pacheco (2010, p. 29): "dados nada dizem sobre a importância ou irrelevância. Porém os dados são importantes para as organizações porque são essenciais para a criação da informação". Ao agregar valor ao dado, a informação complementa a sua definição, tornando-se o segundo pilar da GIC. A informação reduz a incerteza sobre um estado ou sobre um evento, pois apoia o processo decisório, tendo influência sobre o comportamento das pessoas e otimizando os esforços empregados (Moraes \& Fadel, 2008). A informação precisa também ser relevante, clara, consistente e oportuna, conforme observam Rocha Júnior, Guimarães e Jeunon (2014).

Além do dado e da informação, a GIC precisa de um terceiro pilar para consolidar-se: o conhecimento, que "é a mistura fluída da experiência condensada, valores, informação contextual e insight experimentado, a qual proporciona uma estrutura de avaliação e incorporação de novas experiências" (Davenport \& Prusak, 1998, p. 6). No processo de gerenciar conhecimento, Nonaka e Takeuchi (1997) 
observam a importância dos conhecimentos explícitos e tácitos para as organizações, acrescentando ser o conhecimento tácito a base da criação do conhecimento organizacional. A conversão do conhecimento individual em recurso disponível para as pessoas de uma empresa é a atividade central de uma organização orientada para a GIC. O conhecimento tácito é pessoal. Sua formalização é, na maioria dos casos, difícil, e sua transferência para os outros também é árdua. Já o conhecimento explícito é formal e sistemático. Assim, pode ser facilmente comunicado e compartilhado com as demais pessoas da organização.

Empresas criadoras de conhecimento têm, conforme os autores supracitados, interações dinâmicas, propiciando a conversão do conhecimento: socialização (quando a organização favorece a interação entre seus trabalhadores sobre experiências e modelos mentais, viabilizando o compartilhamento do conhecimento); externalização (quando a organização garante a articulação do conhecimento, fomentando diálogos e reflexões, gerando o conhecimento conceitual); combinação (quando a organização viabiliza a inclusão do que foi aprendido em novos produtos e processos, surgindo o conhecimento sistêmico); internalização (quando a organização define a melhor forma de gerenciar seus sistemas, gerando o conhecimento operacional).

Souza, Dias e Nassif (2011, p. 62) definem GIC como "práticas gerenciais que permitem a construção, a disseminação e o uso da informação". Para Davenport e Prusak (1998), é uma gestão realizada pelas etapas de: i) administração de exigências (compreensão clara das necessidades de informação da empresa); ii) plano de ativos informacionais (classificação da informação de acordo com a confiabilidade e sistema de proteção / sigilo); iii) plano de sistemas informacionais (planejamento do armazenamento e distribuição dos dados); iv) aquisição (obtenção da informação); v) análise (avaliação do conteúdo da informação); vi) disseminação (distribuição da informação) e; vii) feedback (verificação se a informação recebida foi adequada e se foi distribuída de maneira correta).

Com a implementação da GIC na empresa, torna-se possível a migração de uma gestão voltada de um controle interno para um modelo fluído, no qual a organização mantém, permanentemente, contato com o ambiente externo, além do interno, e transforma esse conhecimento de mercado em conhecimento explícito. A partir dessa nova dinâmica, torna-se possível também a implementação da IC, conforme será apresentado a seguir.

\subsection{Monitoramento de Mercado e a Inteligência Competitiva}

Ao ser implementada na empresa, a GIC tornase o alicerce para o Monitoramento de Mercado. "O monitoramento trabalha como um radar, orientado para detectar e interpretar os sinais relativos à organização, incluindo uma quantidade de atividades pessoais e organizacionais" (Hoffmann, 2011, p. 5). A organização empenhada em manter o Monitoramento de Mercado pode conquistar vantagens em relação aos concorrentes.

Embora pareça uma atividade complexa e restrita às grandes empresas, o Monitoramento de Mercado é intrínseco a todas as organizações. A diferença básica entre o monitoramento realizado entre empresas de diferentes portes consiste na estrutura disponibilizada para a execução da análise do mercado (Barbosa, 2008).

Nas MPE, a realidade cotidiana distingue-se das grandes empresas, pois não existe uma robusta estrutura disponível para realizar o Monitoramento de Mercado. Mesmo assim, uma MPE não se isenta das influências exercidas permanentemente pelo ambiente externo no negócio e, por isso, deve adaptar o monitoramento às suas possibilidades para se tornar e se manter competitiva. Como Martins (2011) destaca, na MPE, o Monitoramento de Mercado pode concentrar-se na análise de aspectos relacionados à estratégia, direcionando os esforços para implementar a Inteligência Competitiva (IC).

A IC é definida por Bortoluzzi, da Silva, Saciloto e Fachinelli (2014, p. 32) como o "processo de aumentar a vantagem competitiva de uma empresa, com o uso inteligente da informação disponível para a tomada de decisões". Miller (2002) enfatiza que, em função dos múltiplos fatores aos quais as organizações estão suscetíveis, a IC transformou-se em um 'instrumento potencializador' da organização para a tomada de decisões, uma vez que se torna possível identificar cenários que "prenunciam eventos que tragam implicações estratégias para o posicionamento competitivo da empresa" (p. 45). Para Mafra Pereira, Carvalho e Jordão (2016), a IC viabiliza a contínua construção de cenários através de sinais que preveem potenciais modificações no ambiente de negócios da organização, sendo possível planejar e readequar a empresa para enfrentar desafios do ambiente no qual ela encontra-se inserida.

A Tabela 1 apresenta conceitos acerca da IC, baseados em Oliveira e Teles (2015) e Teixeira e Valentim (2016), adaptada e complementada pelos autores deste trabalho, de forma a mapear, ao longo do tempo, evoluções do termo no contexto empresarial. 
Tabela 1 - Conceitos/Definições sobre Inteligência Competitiva

\begin{tabular}{|c|c|}
\hline $\begin{array}{c}\text { Autores / } \\
\text { Entidades }\end{array}$ & Conceito/Definição sobre Inteligência Competitiva \\
\hline $\begin{array}{l}\text { Prescott e Gibbons } \\
\text { (1993) }\end{array}$ & $\begin{array}{l}\text { Processo evolutivo pelo qual a equipe de gestão avalia a evolução e as capacidades da sua } \\
\text { indústria e o comportamento dos seus atuais e potenciais concorrentes para ajudar na manutenção } \\
\text { ou desenvolvimento de uma vantagem competitiva. ('tradução nossa') }\end{array}$ \\
\hline Cubillo (1997) & $\begin{array}{l}\text { Conjunto de capacidades próprias mobilizadas por uma entidade lucrativa, destinadas a assegurar } \\
\text { o acesso, capturar, interpretar e preparar conhecimento e informação com alto valor agregado } \\
\text { para apoiar a tomada de decisão requerida pelo desenho e execução de sua estratégia competitiva. }\end{array}$ \\
\hline Canongia (1998) & $\begin{array}{l}\text { Objetiva agregar valor à informação, fortalecendo seu caráter estratégico, catalisando, assim, o } \\
\text { processo de crescimento organizacional. Nesse sentido, a coleta, tratamento, análise e } \\
\text { contextualização de informação permitem a geração de produtos de inteligência, que facilitam e } \\
\text { otimizam a tomada de decisão no âmbito tático e estratégico. }\end{array}$ \\
\hline Kahane & $\begin{array}{l}\text { Processo de coleta sistemática e ética das informações sobre as atividades dos seus concorrentes } \\
\text { e sobre as tendências gerais do ambiente de negócios, com o objetivo de aperfeiçoar a posição } \\
\text { competitiva da empresa. }\end{array}$ \\
\hline Herring (1999) & $\begin{array}{l}\text { Processo organizacional de coleta e análise da informação, que por sua vez é disseminado como } \\
\text { inteligência aos usuários, em apoio à tomada de decisão, tendo em vista a geração ou sustentação } \\
\text { de vantagens competitivas. }\end{array}$ \\
\hline Battaglia (1999) & $\begin{array}{l}\text { Disciplina capaz de integrar o planejamento estratégico, atividade de marketing e de informação, } \\
\text { objetivando o monitoramento constante do ambiente externo, com respostas rápidas e precisas à } \\
\text { empresa no que diz respeito aos movimentos do mercado. }\end{array}$ \\
\hline $\begin{array}{l}\text { Canongia, Lamb, } \\
\text { Carvalho e } \\
\text { Valdenis (2001) } \\
\end{array}$ & $\begin{array}{l}\text { Conjunto de atividade de monitoramento e de análise de dados do ambiente, com o objetivo de } \\
\text { fornecimento de informações úteis ao processo decisório e ao planejamento empresarial. }\end{array}$ \\
\hline Tarapan & $\begin{array}{l}\text { Nova síntese teórica no tratamento da informação para a tomada de decisão, uma metodologia } \\
\text { que permite o monitoramento informacional da ambiência e, quando sistematizado e analisado, a } \\
\text { tomada de decisão [...] é um processo sistemático que transforma pedações esparsos de dados em } \\
\text { conhecimento estratégico. }\end{array}$ \\
\hline $\begin{array}{l}\text { Krucken-Pereira, } \\
\text { Debiasi e Abreu } \\
\quad(2001)\end{array}$ & $\begin{array}{l}\text { Permite à organização identificar ameaças competitivas, eliminar ou reduzir surpresas, reduzir o } \\
\text { tempo de reação, identificar oportunidades latentes, gerenciar clientes, antecipar necessidades e } \\
\text { desejos dos consumidores, monitorar as estratégias dos concorrentes, difundir as informações na } \\
\text { organização, preservar a vantagem competitiva, monitorar as tecnologias em desenvolvimento, } \\
\text { dentre outras ações. }\end{array}$ \\
\hline $\begin{array}{r}\text { Prescott } \mathrm{e} \\
\qquad(200\end{array}$ & $\begin{array}{l}\text { O acompanhamento das intenções dos concorrentes e de ocorrências imprevistas no mercado } \\
\text { pelo exame de registros públicos; monitoramento atento da Internet e dos meios de comunicação } \\
\text { de massa; contato com clientes, fornecedores, parceiros, especialistas do setor e outras fontes } \\
\text { confiáveis; criação de perfis psicológicos de tomadores de decisão de alto nível e participação em } \\
\text { feiras e congressos - com o objetivo de reunir dados relativos ao que os concorrentes estão } \\
\text { fazendo e incorporar esse conhecimento ao planejamento dos negócios. }\end{array}$ \\
\hline Miller (2002) & $\begin{array}{l}\text { Monitoração de uma ampla gama de fatos novos ao longo do ambiente ou mercado externos de } \\
\text { uma organização e seus negócios [...] concentra-se nas perspectivas atuais e potenciais quanto a } \\
\text { pontos fortes, fracos e nas atividades de organizações que tenham produtos ou serviços similares } \\
\text { dentro de um setor da economia. }\end{array}$ \\
\hline Borges & $\begin{array}{l}\text { Conjunto de atividades voltadas para a obtenção, para o processamento, a análise e a } \\
\text { disseminação de informação acerca do ambiente de negócios de organizações de produção, com } \\
\text { o objetivo de dar suporte à tomada de decisão e à definição estratégica. }\end{array}$ \\
\hline Valentim (2002) & $\begin{array}{l}\text { Ligada ao conceito de processo contínuo, sua maior complexidade está no fato de estabelecer } \\
\text { relações e conexões de forma a gerar inteligência para a organização, na medida em que cria } \\
\text { estratégias para cenários futuros e possibilita tomada de decisão de maneira mais segura e } \\
\text { assertiva. }\end{array}$ \\
\hline $\begin{array}{c}\text { Valentim e } \\
\text { Cervantes (2003) }\end{array}$ & $\begin{array}{l}\text { Processo que investiga o ambiente onde a empresa está inserida, com o propósito de descobrir } \\
\text { oportunidades e reduzir os riscos, bem como diagnostica o ambiente interno organizacional, } \\
\text { visando o estabelecimento de estratégias de ação a curto, médio e longo prazo. }\end{array}$ \\
\hline $\begin{array}{l}\text { Cardoso Júnior } \\
\qquad(2003)\end{array}$ & $\begin{array}{l}\text { Representa uma ferramenta estratégica que permite à alta gerência melhorar sua competitividade, } \\
\text { identificando as principais forças propulsoras e prevendo os futuros rumos do mercado. É um } \\
\text { processo pelo qual as informações de múltiplas fontes são coletadas, interpretadas e comunicadas }\end{array}$ \\
\hline
\end{tabular}




\begin{tabular}{|c|c|}
\hline & a decidir. \\
\hline $\begin{array}{l}\text { Gomes e Braga } \\
\quad(2004)\end{array}$ & $\begin{array}{l}\text { Resultado da análise de dados e informações coletados do ambiente competitivo da empresa que } \\
\text { irão embasar a tomada de decisão, pois gera recomendações que consideram eventos futuros e } \\
\text { não somente relatórios para justificar decisões passadas. }\end{array}$ \\
\hline $\begin{array}{l}\text { Nadaes e Borges } \\
\quad(2005)\end{array}$ & $\begin{array}{l}\text { Processo de coleta e análise sistemática de informações que gera subsídios para a tomada de } \\
\text { decisão organizacional. A habilidade com que a empresa coleta, organiza, analisa e implementa } \\
\text { mudanças a partir de informações estratégicas, integrando-as ao processo de melhoria contínua } \\
\text { de suas atividades, determinará a sua excelência frente ao ambiente de negócios. }\end{array}$ \\
\hline Lodi (2006) & $\begin{array}{l}\text { Processo contínuo e interativo que tem como objetivo coletar, analisar e disseminar informações } \\
\text { relevantes, precisas e oportunas para a tomada de decisão nos negócios. }\end{array}$ \\
\hline Tarapanoff (2006) & $\begin{array}{l}\text { vado pela competição, fundado sobre a informação, permitindo esta } \\
\text { gia corporativa em curto e em longo prazo. }\end{array}$ \\
\hline $\begin{array}{l}\text { Tena Millán e } \\
\text { Comai (2006) }\end{array}$ & $\begin{array}{l}\text { Processo sistemático de busca, seleção, análise e distribuição de informação sobre o ambiente, } \\
\text { reconhecido e aceito em toda a organização. um processo de identificação, coleta, tratamento, } \\
\text { análise e disseminação da informação estratégica para a organização que viabiliza a tomada de } \\
\text { decisão. }\end{array}$ \\
\hline Fuld (2007) & c̃ão analisada que oferece à empresa insights e vantagem competitiva. \\
\hline Starec (2012) & $\begin{array}{l}\text { Processo sistemático de coleta, tratamento, análise e disseminação da informação sobre } \\
\text { atividades dos concorrentes, fornecedores, clientes, tecnologias e tendências gerais dos negócios, } \\
\text { visando subsidiar a tomada de decisões e atingir as metas estratégicas da empresa. É conduzida, a } \\
\text { partir de uma orientação estratégica, para a obtenção de vantagem competitiva. }\end{array}$ \\
\hline Oliveira (2013) & $\begin{array}{l}\text { Processo voltado para a transformação de dados e informações esparsas sobre os concorrentes e } \\
\text { demais eventos de interesse dos ambientes interno (forças e fraquezas) e de negócios (ameaças e } \\
\text { oportunidades) em produtos de inteligência acionáveis para os tomadores de decisões } \\
\text { estratégicas. }\end{array}$ \\
\hline $\begin{array}{l}\text { Silva e De Muylder } \\
\text { (2015) }\end{array}$ & $\begin{array}{l}\text { Processo sistemático que transforma pedações esparsos de dados em conhecimento estratégico. É } \\
\text { informação sobre produtos específicos e tecnologia, é monitoramento de informações externas } \\
\text { que afetam o mercado da organização, como a informação econômica, regulatória, política e } \\
\text { demográfica. }\end{array}$ \\
\hline SCIP & $\begin{array}{l}\text { Programa sistemático e ético de reunir, analisar e gerenciar informação externa, que pode afetar } \\
\text { os planos, decisões e operações de uma organização no mercado, por meio de um entendimento } \\
\text { maior, mas inequivocamente ético, dos seus competidores e do seu ambiente competitivo. } \\
\text { (tradução nossa) }\end{array}$ \\
\hline ABRAIC (2016) & $\begin{array}{l}\text { Processo informacional proativo que conduz à melhor tomada de decisão, seja ela estratégica ou } \\
\text { operacional. É um processo sistemático que visa descobrir as forças que regem os negócios, } \\
\text { reduzir o risco e conduzir o tomador de decisão a agir antecipadamente, bem como proteger o } \\
\text { conhecimento gerado. }\end{array}$ \\
\hline
\end{tabular}

Fonte: Elaborado e adaptado pelos autores, com base em Oliveira e Teles (2015) e Teixeira e Valentim (2016).

A IC, nas grandes empresas, se constitui num sistema mais estruturado e formal, se assemelhando mais proximamente às definições e modelos encontrados na literatura. Entretanto, vale ressaltar que a IC está deixando de ser exclusiva das grandes corporações para fazer parte do universo dos pequenos negócios. Destacam-se, neste sentido, os trabalhos recentes de Vitorino e Garcia (2013), Pereira e Perez (2015), Coutinho e Ramos (2015), Mafra Pereira, Borges e Jordão (2015), Mafra Pereira e Santos (2015), Oliveira e Sade (2016) e Mafra Pereira, Carvalho, Neves e Quintão (2017), que demonstram o crescimento e o uso da IC no universo dos pequenos negócios. Ao ser implementada na MPE, a IC potencializa a competitividade da organização no mercado ao selecionar as informações que são relevantes ao negócio, auxiliando o proprietário na gestão acertada do empreendimento (Mafra Pereira \& Santos, 2015).

A sistematização da IC torna-se necessária devido à enxurrada de dados com a qual os gestores se deparam diariamente (Bairle, Frozza, Nara \& Kipper, 2011), conseguindo filtrar pouca coisa para transformálos em informação relevante e prioritária para a elaboração de suas estratégias e tomada de decisão. Tal sistematização pode ser realizada por meio de etapas/subprocessos, definidos na literatura como "Ciclo de Inteligência Competitiva", variando no número de etapas/subprocessos, dependendo da referência utilizada (Martre, 1994; Herring, 1999; Miller, 2002; Calof \& Wright, 2008; Starec, 2012). Mafra Pereira, Carvalho e Jordão (2016), em estudo 
sobre a estruturação e implantação de um Bureau de IC em Arranjos Produtivos Locais (APL), adotaram o modelo de Amaral, Garcia e Alliprandini (2008), com 6 etapas: 1) Identificação das necessidades de informação; 2) Planejamento; 3) Coleta das informações; 4) Análise; 5) Disseminação e; 6) Avaliação (Figura 1), o qual também foi adotado neste trabalho como referência para o estudo sobre a IC nas MPE da Aerotrópole de Belo Horizonte.

Figura 1 - Ciclo de Inteligência Competitiva

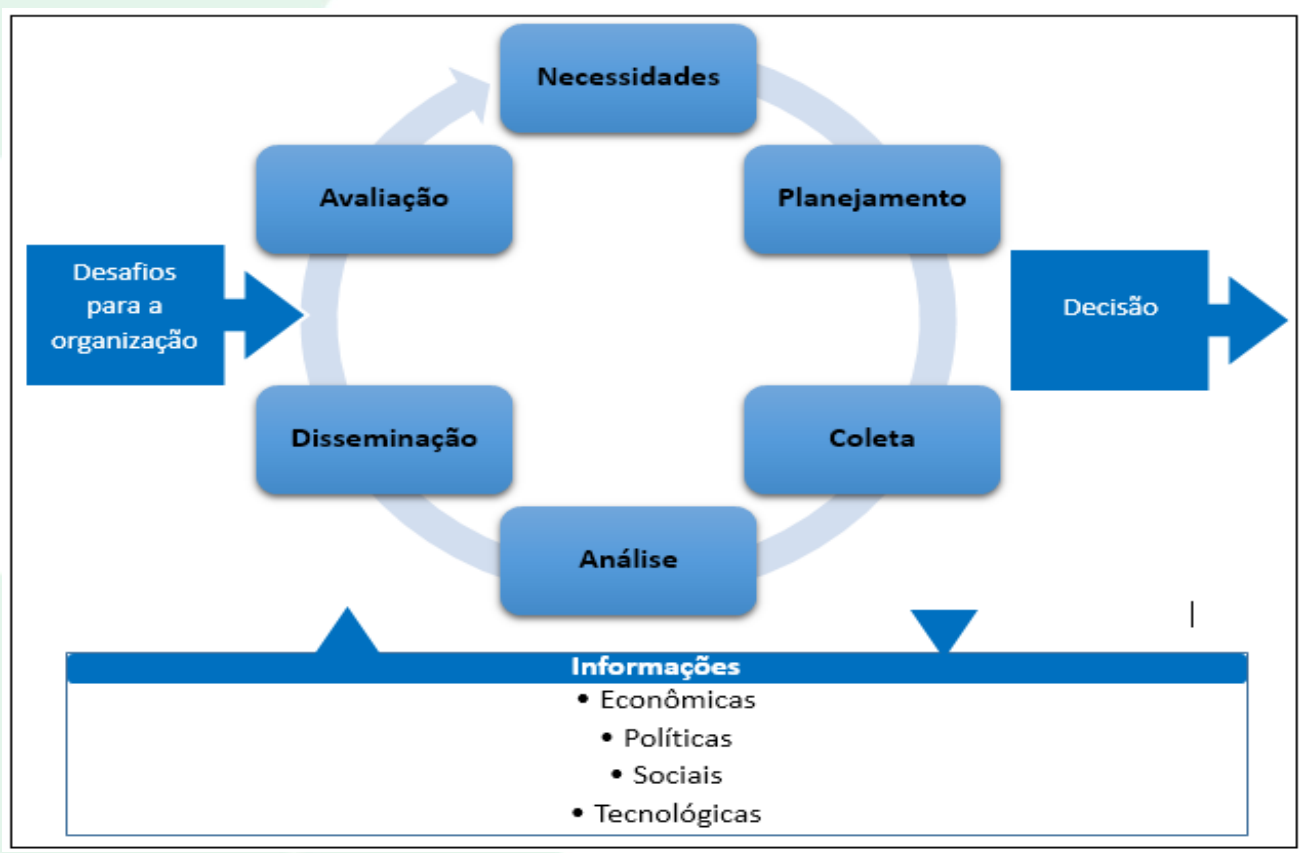

Fonte: Adaptado por Mafra Pereira, Carvalho e Jordão (2016), com base em Amaral, Garcia e Alliprandini (2008).

O $1^{\circ}$ subprocesso corresponde à identificação e mapeamento das necessidades informacionais, gerando os "Tópicos-Chave de Inteligência", ou KIT (Key Intelligence Topics), e as Questões-Chave de Inteligência, ou KIQ (Key Intelligence Questions) (Herring, 1999). Segundo Mafra Pereira, Carvalho e Jordão (2016), os KIT proporcionam foco e priorização da IC para os temas informacionais considerados mais importantes pela organização, além de ajudarem na própria estruturação da atividade.

O $2^{\mathbf{0}}$ subprocesso corresponde ao planejamento, onde é definida e organizada a forma como o trabalho será desenvolvido: previsão de atividades, definição das fontes de informação necessárias para a etapa de Coleta, métodos analíticos a serem utilizados na etapa de Análise, equipe envolvida, prazos para entrega dos Produtos de IC, e recursos necessários para sua execução (humanos, financeiros e estruturais).

Na coleta de dados, Bairle, Frozza, Nara e Kipper (2011) destacam que os dados levantados são "inteligência bruta" e precisarão ser trabalhados para que possam ser utilizados na formulação de estratégias e tomada de decisões. Mafra Pereira, Carvalho e Jordão (2016) complementam que neste subprocesso são realizadas as etapas de busca, adequação e processamento das informações úteis à resolução dos KIT e KIQ anteriormente definidos.

No subprocesso de análise, os dados e informações coletados são transformados, de fato, em inteligência. Mafra Pereira, Carvalho e Jordão (2016) consideram esta etapa como o "coração" da atividade de Inteligência, quando as informações coletadas são, de fato, transformadas em avaliações significativas, visando seu impacto positivo na busca de posição competitiva da organização. Bairle, Frozza, Nara e Kipper (2011) destacam o uso de técnicas de análise diversas e a capacidade do raciocínio humano de avaliar a relevância e a credibilidade das informações, sendo um dos pontos mais críticos da IC.

O $5^{\circ}$ subprocesso corresponde à Disseminação da Inteligência, com a entrega dos Produtos de IC e a definição das estratégias de comunicação e disponibilização da inteligência aos usuários, conforme seus perfis e preferências (Mafra Pereira, Carvalho \& Jordão, 2016). Nela ocorre também a apresentação das alternativas de ações disponíveis para a organização, considerando-se as limitações da organização em executá-las e a reação mais provável do ambiente a cada uma delas. Para Starec (2012), a disseminação pode se dar por meio verbal ou formal, mas é importante que as informações fiquem disponíveis para todos os níveis e/ou setores da organização. 
O último subprocesso, da Avaliação, é quando o gestor de IC se preocupa em reconhecer e validar as pessoas que participaram do processo. Mafra Pereira, Carvalho e Jordão (2016) advertem que não só é importante avaliar se a atividade de IC está cumprindo com o que foi planejado em termos de trabalho e entregas, mas também conseguir perceber e medir se a IC está efetivamente sendo utilizada nos processos de tomada de decisão da organização, e se é considerada estratégica pelos usuários que fazem uso dela. Bairle, Frozza, Nara e Kipper (2011) afirmam que a avaliação é imprescindível tanto para o constante desenvolvimento e aprimoramento do processo, como para a própria sobrevivência dele, uma vez que a IC só se consolida quando seus resultados são efetivamente utilizados para a tomada de decisões.

Embora o "Ciclo de Inteligência Competitiva" pareça complexo e restrito a grandes corporações, ele pode ser adaptado à realidade das MPE, que dispõem de uma estrutura enxuta, se comparada às grandes organizações. Essa estrutura enxuta dá às MPE a vantagem de, a partir da implementação da IC, terem tomadas de decisões ágeis, e respaldadas por informações do meio ambiente externo que interferem no negócio (Pearce, Chapman \& David, 1982). Com decisões respaldadas pela IC, a MPE passa a orientar a Estratégia Empresarial também com maior assertividade. Assim, o "Ciclo de Inteligência Competitiva" torna-se um sistema de aprendizagem no qual as informações são aplicadas na Estratégia Empresarial para a melhoria do desempenho organizacional.

\subsection{Estratégia Empresarial em MPE}

Segundo Mintzberg (2007), a Estratégia Empresarial determina/mapeia a direção que a organização deve seguir mediante seus esforços. De acordo com Alves, Antonialli, Lopes, Souki e Reis Neto (2013), a Estratégia Empresarial não se restringe às grandes empresas. Ela abrange todos os tipos de organizações ou instituições, independente do porte, ramo de atividade e natureza de operações.

A Estratégia Empresarial embasada pela IC transforma-se em um elemento fundamental para que as MPE gerem valor superior aos concorrentes, diferenciando-se no disputado mercado. Quanto mais aprimorado for o conjunto de suposições e hipóteses que a empresa reúna, a partir do acompanhamento sistemático do mercado, maiores são as chances de alcançar a vantagem competitiva (Mintzberg, 1987; Porter, 1996; Barney \& Hesterly, 2007).

Segundo Harrison (2002), a Estratégia Empresarial precisa, impreterivelmente, contemplar o ambiente interno e externo, para "mover a organização e implementar as estratégias, tudo em um esforço para satisfazer a seus principais públicos interessados" (p.26). A gestão da empresa deve elencar suas estratégias levando em consideração as oportunidades que o mercado oferece, os pontos fortes que a estrutura proporciona e maneiras de neutralizar as ameaças ambientais, além de também aprimorar seus pontos fracos.

Mintzberg (2007) conceitua estratégia através de 5P's: plan (plano, guia, curso de ação, caminho a ser seguido entre o estado atual e o estado futuro desejado); pattern (padrão, comportamento consistência ao longo do tempo); position (posição de certos produtos em determinados mercados); perspective (perspectiva através da qual a organização age); ploy (estratagema, manobra específica para vencer o concorrente).

Por Estratégia Empresarial entende-se o "conjunto de regras de tomada de decisão para orientação do comportamento de uma organização" (Ansoff \& McDonell, 1993, p. 47). É a capacidade de entender o mercado e a habilidade para comandar ativos intangíveis como conceitos, capacidades, bem com conexões locais, regionais e até mundiais (Kanter, 1995).

Uma estratégia em MPE pode emergir, segundo Alves, Antonialli, Lopes, Souki e Reis Neto (2013), como uma situação em evolução ou pode ser introduzida deliberadamente, por meio de um processo de formulação seguido de implementação. As estratégias emergentes são ações praticadas na dinâmica das organizações, sem terem sido planejadas. Uma vez bem-sucedidas, passam a se integram ao esforço de planejamento da organização.

Segundo Gimenez, Pelisson, Krüger e Hayashi Jr (1999), a estratégia em MPE é fortemente influenciada por uma abordagem empreendedora, que reconhece a influência do comportamento individual do proprietário sobre o processo de formação de estratégia. Ou seja, a criação da estratégia tende, muitas vezes, a refletir a visão implícita de que este dono tem do mundo, transformando a estratégia até em uma extrapolação de sua personalidade. Vale ressaltar que tal situação pode causar problemas de gerenciamento em função de uma baixa qualificação acadêmica, uma divisão de tarefas que não se apresenta nítida e um potencial acúmulo de funções. Além destes desafios, as MPE ainda enfrentam outros obstáculos, como a pouca capacidade financeira e a deficitária modernização tecnológica, que não permite a implementação da inovação.

Para a formulação da estratégia em MPE, faz-se necessária a percepção de diversificados fatores internos ou externos que, necessariamente, interagem com a empresa. Portanto, tal percepção, se embasada pela IC, conforme seus conceitos e processos apresentados anteriormente, pode proporcionar maior assertividade na formulação da estratégia. 


\subsection{Modelo Teórico-Analítico: Competitividade para MPE}

Com base no referencial teórico, chega-se à proposição de um Modelo Teórico-Analítico de integração entre a GIC, a IC e a Estratégia Empresarial (Figura 2), que constitui a base da pesquisa ora realizada, dando subsídio à coleta e à análise dos dados.

Figura 2 - Modelo Teórico-Analítico: Competitividade para MPE

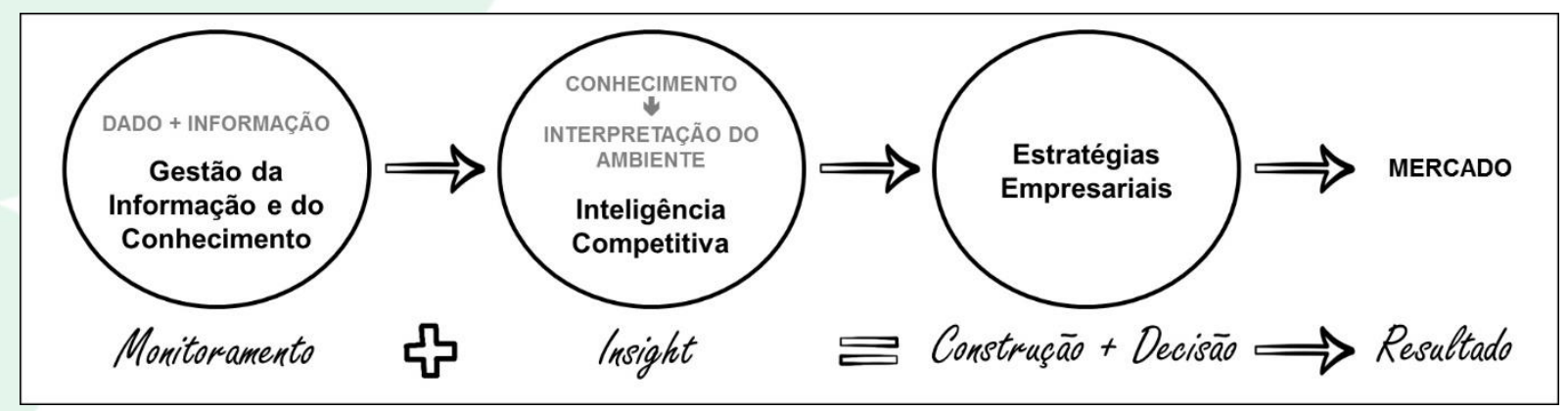

Fonte: Elaborado pelos autores.

A GIC, na primeira fase do Modelo TeóricoAnalítico, pode proporcionar que as MPE compreendam, com maior exatidão, o mercado. Através da organização da miscelânea de dados e informações existentes no ambiente da Aerotrópole de Belo Horizonte (contexto desta pesquisa), a organização de micro e pequeno porte pode realizar o Monitoramento de Mercado, gerando o conhecimento, que é a base para a implementação da IC. Com a IC, as MPE podem interpretar o contexto da Aerotrópole de Belo Horizonte, no qual se encontram inseridas, e gerar insights, ou seja, ideias que alicerçarão suas Estratégias Empresariais.

Assim, as estratégias, construídas a partir da IC, contemplarão as variadas nuances do mercado regional e, consequentemente, proporcionarão maior assertividade nas decisões empresariais e permitirão que as pequenas organizações possam se rearranjar internamente para posicionarem-se de maneira assertiva frente aos múltiplos desafios do competitivo mercado da Aerotrópole de Belo Horizonte, gerando, potencialmente, um resultado satisfatório, como maior competitividade, rentabilidade e maximização de lucros.

\section{MÉTODO}

Para alcançar os objetivos do estudo, foi realizada pesquisa do tipo descritiva (Collis \& Hussey, 2005; Malhotra, 2006; Vergara, 2014), para conhecimento e interpretação da realidade, utilizandose da abordagem qualitativa (Creswell, 1994; Gil, 2002), com foco nas impressões manifestadas pelos atores envolvidos.

Com o foco de analisar como se configura a IC nas MPE da Aerotrópole de Belo Horizonte com vistas à elaboração de suas Estratégias Empresariais, utilizou- se da pesquisa de campo para a coleta dos dados como técnica principal, por meio da realização de entrevistas individuais, conduzidas por roteiros semiestruturados (Triviños, 1987).

A definição das unidades de análise desta pesquisa (Yin, 1984; Mazzotti \& Gewandsznajder, 1999; Bressan, 2000; Kasarda \& Lindsay, 2012) considerou as MPE dentro da área de influência (raio de 30 quilômetros a partir do Aeroporto) da Aerotrópole de Belo Horizonte. No momento inicial, projetou-se uma amostra de 2 empresas por segmento (indústria, comércio e serviços), considerando os sete municípios compreendidos na área de influência (Capim Branco, Confins, Matozinhos, Lagoa Santa, Pedro Leopoldo, São José da Lapa e Vespasiano), e que tivessem no mínimo 5 anos de mercado (visando à profundidade, segurança e clareza nos dados levantados). Isso foi feito. Todavia, nenhuma indústria abordada demonstrou interesse em participar da coleta de dados.

Dessa forma, foram selecionadas 28 empresas para a pesquisa, sendo 14 MPE do setor secundário (comércio) e 14 MPE do setor terciário (serviços). Foram entrevistados os 28 proprietários das MPE selecionadas (unidades de observação) (Gil, 2002), por estarem estes à frente dos negócios, além de desenvolverem e participarem da maioria das estratégias e tarefas das pequenas organizações, tendo, assim, domínio para responder às perguntas definidas no roteiro semiestruturado. A amostragem, portanto, foi do tipo não probabilística convencional (ou intencional) (Mattar, 1996; Malhotra 2006), dados os parâmetros de inclusão mencionados acima.

A coleta de dados foi caracterizada pela triangulação de fontes de coleta de dados qualitativos, oriundas das entrevistas com os proprietários das 28 MPE, da observação participante e da pesquisa documental, comparando informações extraídas de 
diversas fontes de evidência, confrontando-as entre si como forma de aumentar a credibilidade na interpretação a posteriori dos resultados (validade interna), aumentando também a possibilidade de generalização do estudo e a minimização dos vieses pessoais que porventura pudessem existir (Vergara, 2014).

A coleta de dados através das entrevistas individuais se baseou na aplicação de em um roteiro semiestruturado, a cada um dos 28 entrevistados, que continha 10 perguntas abertas, com o objetivo de: i) identificar as práticas de monitoramento do ambiente / Inteligência Competitiva realizadas pelas MPE da Aerotrópole de Belo Horizonte; ii) identificar como tais MPE planejam e implementam suas Estratégias Empresariais na Aerotrópole de Belo Horizonte e; iii) identificar o nível de percepção dessas MPE sobre a Aerotrópole de Belo Horizonte. Além disso, levantouse também o perfil dos respondentes, e as principais características das empresas, como será demonstrado no item sobre a análise dos dados.

Com relação à observação participante, Sanday (1984) afirma que o observador participante deve aprender a usar sua própria pessoa como o principal e mais confiável instrumento de observação, seleção, coordenação e interpretação, interagindo com os sujeitos da pesquisa, e se tornando parte da situação observada. Para Oliveira (2010), o pesquisador faz parte da pesquisa qualitativa, sendo ele o primeiro instrumento da própria pesquisa, pois traz consigo a bagagem intelectual e experiência de vida, traduzindo a pesquisa através das características culturais, políticas, religiosas, étnicas, e até da idade que carrega. Também Creswell (1994) afirma ser essencial que as observações se conectem às entrevistas, de maneira complementar, proporcionando, com assertividade, o reflexo da realidade. Considerando o contexto da Aerotrópole de Belo Horizonte, todos os autores deste trabalho atuam diretamente junto às empresas e entidades representativas destas na região, o que corroborou para que esta técnica também pudesse ser considerada, não somente na coleta de dados, como também na análise posterior realizada.

Por último, a técnica de pesquisa documental (Gil, 2002; Figueiredo, 2007) foi utilizada como meio de confirmar as informações obtidas através das entrevistas individuais e da observação participante, via documentos acessados, consultados e analisados em toda a extensão dos itens que representaram este trabalho.

Portanto, a escolha pela triangulação de fontes de dados qualitativos condiz com o que é afirmado por Benbasat, Goldstein e Mead (1987): i) uma ou mais entidades (pessoa, grupo, organização) podem ser analisadas simultaneamente; ii) os fenômenos podem observados em seu ambiente natural; iii) os dados são recolhidos utilizando-se de diversos meios (observações diretas, entrevistas, registros de áudio e vídeos, diários, entre outros) e; iv) a complexidade da unidade é estudada de forma aprofundada.

As técnicas de análise de dados foram do tipo Análise de Conteúdo e de Observação. De acordo com Tjora (2006), entrevistas e observação são técnicas interativas, e a entrevista conduz o pesquisador para a observação, a qual pode sugerir os aprofundamentos necessários para as entrevistas. A observação permite também a detecção e obtenção de informações por vezes não apreendidas por outros métodos. Já com relação à Análise de Conteúdo (Roesch, 2009), conceituada como "um conjunto de técnicas de análise das comunicações" (Bardin, 2011, p. 31), a palavra possui um significado preponderante neste tipo de análise, que conta com a inferência sobre o objeto analisado.

\section{APRESENTAÇÃO E DISCUSSÃO DOS RESULTADOS}

Os resultados obtidos e suas respectivas análises são apresentados e discutidos em duas partes principais: perfil dos sujeitos da pesquisa e apresentação e análises por objetivo específico.

\subsection{Perfil dos Sujeitos da Pesquisa}

As empresas participantes, conforme planejamento da pesquisa, localizam-se na área de influência do Aeroporto Internacional Tancredo Neves - Confins (centro da Aerotrópole de Belo Horizonte), nos municípios de Capim Branco, Confins, Matozinhos, Lagoa Santa, Pedro Leopoldo, São José da Lapa e Vespasiano.

Foram pesquisadas duas empresas do setor secundário (comércio) e duas do setor terciário (serviços) em cada município, sendo 26 microempresas e 2 pequenas empresas. Em relação ao quadro de funcionários, 11 empresas têm até 5 funcionários, 10 delas têm até 10 funcionários e 7 têm acima de 10 funcionários.

Segundo Leone e Leone (2012), as empresas podem ser classificadas quanto ao seu tamanho, à propriedade, ao controle, ao capital, à idade, ao setor de atuação, à sua área de atuação, sua relação com o mercado externo, à governança corporativa e às suas responsabilidades social e ambiental. Entretanto, as definições mais utilizadas pela maioria dos países do globo, incluindo o Brasil, são as baseadas no número de empregados ou no faturamento.

Neste trabalho, foi utilizada a classificação proposta e adotada pelo SEBRAE (2014), que caracteriza como microempresa aquela com até nove pessoas ocupadas nas atividades de comércio e serviços, como pequena empresa aquela que possui entre 10 e 49 pessoas ocupadas, como média empresa aquela que possui entre 50 e 99 pessoas ocupadas, e como grande empresa aquela que possui 100 pessoas 
ou mais ocupadas. $\mathrm{Na}$ atividade industrial estes critérios são diferentes: para microempresa (até 19 pessoas ocupadas), pequena empresa (entre 20 a 99 pessoas ocupadas), média empresa (entre 100 e 499 pessoas ocupadas) e grande empresa (acima de 500 pessoas ocupadas). Como neste trabalho não foram pesquisadas empresas do segmento industrial, foi considerado o critério de classificação por número de pessoas ocupadas para os setores do comércio e de serviços.

Retomando, sobre os proprietários que participaram das entrevistas: i) Escolaridade: 14 entrevistados possuem ensino médio completo, 2 possuem ensino superior incompleto, 11 possuem a graduação superior completa, e apenas 1 possui formação em nível de mestrado; ii) Idade: apenas 2 empresários possuem menos de 30 anos, 12 empresários possuem entre 30 e 40 anos, e 14 possuem idade entre 40 e 53 anos.

\subsection{Apresentação e Análises por Objetivo Específico}

Com base nos dados e informações coletados através da metodologia de triangulação de fontes de coleta e análise dos dados, os resultados serão apresentados e analisados considerando os principais elementos do Modelo Teórico-Analítico proposto, sob a ótica dos três objetivos específicos da pesquisa.

\subsubsection{Identificação das práticas de monitoramento do ambiente/Inteligência Competitiva realizadas pelas MPE da Aerotrópole de Belo Horizonte}

Considerando a apresentação e a análise das informações obtidas a partir das entrevistas individuais realizadas junto aos proprietários de MPE da Aerotrópole de Belo Horizonte, além da análise de documentos correspondentes e da observação participante, em relação à pergunta "Que tipos de informações você considera importantes ter em mãos para a tomada de decisões em sua empresa?", tem-se que:

- Os entrevistados priorizam a busca por informações para aprimorar os processos operacionais/internos das organizações;

- Em função da proximidade com os clientes e fornecedores, estes se tornam importantes fontes de informação para os entrevistados;

- Poucos gestores enxergam os concorrentes como fator preponderante ao negócio.

A Tabela 2 mostra uma síntese de algumas afirmações dos respondentes sobre esta questão.

Tabela 2 - Síntese sobre os tipos de informação para a tomada de decisão

\begin{tabular}{l|l|l}
\hline \multicolumn{1}{c|}{ MUNICÍPIO } & SETOR & AFIRMAÇÃO \\
\hline Capim Branco & Comércio & "Escutar o cliente é o que move a empresa." \\
\hline Confins & Comércio & "Busco todos os dias informações sobre o meu negócio." \\
\hline Matozinhos & Serviços & "Sempre recebo os fornecedores para conversar." \\
\hline Lagoa Santa & Serviços & "Ouço com atenção o que os clientes querem." \\
\hline Pedro Leopoldo & Comércio & "Converso bastante com os clientes." \\
\hline São José da Lapa & Comércio & "Sempre estou em busca de informações para fazer as coisas melhores." \\
\hline Vespasiano & Comércio & "Sempre estou de olho no que meu concorrente está fazendo." \\
\hline
\end{tabular}

Fonte: Dados da pesquisa (2016).

Como as informações relevantes para os proprietários das MPE entrevistados são aquelas relacionadas ao negócio, observa-se que eles priorizam a busca por informações para aprimorar os processos operacionais/internos das suas organizações, com preferência por fontes primárias pessoais. Dessa forma, fica em segundo plano a busca por informações para melhor entendimento do ambiente externo de negócios, incluindo as ameaças e as oportunidades que podem impactar o desempenho destas empresas no futuro.

Sobre as respostas às questões "Como sua você/ sua empresa coleta essas informações? Quais os meios/fontes de informação são mais utilizadas para este fim? Quais os meios a empresa usa para coletar estas informações?":
- Os canais apontados como aqueles utilizados pelos entrevistados para selecionar as informações que influenciam nos negócios são diálogos com clientes, fornecedores e funcionários, especialmente pautados por assuntos relacionados ao nível operacional;

- Poucos entrevistados buscam informações estratégicas relevantes junto a entidades de classe ou representativas de setores econômicos, como o CDL (Câmara de Dirigentes Lojistas) ou o SEBRAE MG (Serviço Brasileiro de Apoio às Micro e Pequenas Empresas de Minas Gerais), por exemplo;

- Os concorrentes não são mencionados como um dos principais canais de coleta de 
informações. Em alguns casos, os gestores observam apenas preços praticados;

- Para que os empresários monitorem o mercado, eles se valem de canais de comunicação de massa, como Internet, jornais, televisão, rádio e revistas.

Percebe-se que os meios/fontes de informação utilizados pelos proprietários das MPE da Aerotrópole de Belo Horizonte são aqueles mais pessoais e informais, conforme apontado em trabalhos de Mafra Pereira (2008; 2016) e Mafra Pereira e Barbosa (2009) sobre Fontes de Informação para Negócios. Dessa forma, as informações coletadas se caracterizam como de curto prazo, com base no dia a dia dos negócios abordados, e não com foco no longo prazo, essenciais para a elaboração de estratégias empresariais.

Além disso, verifica-se também que os entrevistados não se utilizam de fontes de informação mais formais e advindas de entidades de classe e/ou representativas dos seus setores de atuação, o que também compromete a coleta de informações mais bem elaboradas, ou produzidas a partir de estudos e pesquisas técnicas e aplicadas. Por último, a utilização de canais de comunicação de massa acaba padronizando as informações coletadas e consideradas pelas empresas participantes, o que, no contexto da IC e da elaboração de Estratégias Empresariais futuras, não permite a identificação de oportunidades e/ou ameaças diferenciadas sobre o seu mercado e o ambiente de negócios no qual estão inseridas.

No tocante às questões "Como você/sua empresa analisa as informações obtidas através dessas fontes/meios utilizados? As informações obtidas são armazenadas/registradas na empresa para serem utilizadas futuramente? Se sim, como isso é feito? Se não, por que isso não é feito?", verificou-se que:

- Com uma coleta de informações centralizada nos gestores da empresa, a análise destas informações acontece na mente dos proprietários de todas as empresas pesquisadas;

- As informações estratégicas de quase a totalidade das empresas pesquisadas são registradas e armazenadas pelos gestores em cadernos ou agendas;

- Após a coleta e a análise das informações, eles reúnem, manualmente, as informações relevantes com o objetivo de analisá-las e esboçar, minimamente, um planejamento;

- A maioria dos gestores pesquisados analisa as informações no escritório, quando se encontra em momentos com menor possibilidade de interferência, e também na residência deles;

- Detectou-se também a presença de softwares para controles operacionais, porém, há pouquíssima exploração do potencial destes para a geração de conhecimento.

Na prática, percebe-se não existir um processo formal ou padronizado para análise das informações coletadas pelos proprietários das MPE entrevistadas, o que acaba limitando a troca ou o repasse de informações sobre o negócio para outras pessoas da empresa, o que, em tese, limita a geração de inteligência para o negócio, a partir da análise das informações, conforme apontado por Bairle, Frozza, Nara e Kipper (2011), Starec (2012) e Mafra Pereira, Carvalho e Jordão (2016). Em outras palavras, o conhecimento do gestor fica limitado apenas a ele mesmo, não havendo transferência de conhecimento organizacional (Nonaka \& Takeuchi, 1997; Barbalho, Valentim \& Hoffmann, 2007; Souza, Dias \& Nassif, 2011).

Outro aspecto limitador dessa etapa de análise de informações é que os proprietários entrevistados realizam tal atividade quando conseguem tempo ou estão em ambientes mais informais. Ou seja, a falta de formalização deste processo acaba colocando esta atividade em segundo plano na agenda de prioridades dos proprietários entrevistados, sendo estes, na maior parte do seu tempo, consumidos com demandas e ações de curto prazo e operacionais, e não de longo prazo e mais estratégicas. Tais constatações, entretanto, confirmam as visões de Gimenez, Pelisson, Krüger e Hayashi Jr (1999) e de Alves, Antonialli, Lopes, Souki e Reis Neto (2013) sobre a falta de processos mais estruturados e antecipativos para elaboração de estratégias empresariais, sendo estas muito mais emergentes e baseadas nas características empreendedoras dos proprietários das MPE entrevistadas.

Com relação ao registro das informações coletadas, não são utilizados softwares ou sistemas de informação dedicados a essa finalidade mais estratégica. Os sistemas, quando existem, são voltados à gestão de processos operacionais da empresa. Dessa forma, o registro, quando realizado, concentra-se no uso de artefatos analógicos, ou manuais, como agendas e cadernos, os quais, na prática, dificultam a recuperação da informação para uso posterior (Davenport \& Prusak, 1998).

Face ao levantamento realizado sobre o item em questão, constatou-se que o "Ciclo de Inteligência Competitiva", considerado neste trabalho, não é integralmente realizado nas MPE pesquisadas. Observou-se que as etapas de necessidade, planejamento, coleta e análise são executadas, mas de maneira informal, pelos próprios gestores. Já as etapas de disseminação e avaliação, de fato, não são realizadas, uma vez que as informações operacionais e estratégicas das organizações se concentram com os proprietários. A recuperação da informação, quando necessário, não é fácil e nem ágil. 


\subsubsection{Identificação da forma de planejamento $e$ implementação das Estratégias Empresariais pelas MPE na Aerotrópole de Belo Horizonte}

Considerando a pergunta "Você/sua empresa leva em consideração as informações sobre o mercado, o ambiente de negócios em geral, para elaborar estratégias e/ou metas para o negócio?", e pela análise do conteúdo das entrevistas, da análise de documentos referentes ao tema, e da observação participante, verificou-se que:
- A maioria dos entrevistados leva em consideração somente informações sobre a macroeconomia para a elaboração de Estratégias Empresariais;

- Essas informações são obtidas, especialmente, através de fontes secundárias - canais de comunicação de massa, como telejornais, emissoras de rádios, jornais e revistas.

A Tabela 3 apresenta uma síntese das afirmações dos respondentes sobre o uso de informações para a elaboração de Estratégias Empresariais.

Tabela 3 - Síntese sobre o uso de informações para elaboração de Estratégias Empresariais

\begin{tabular}{l|l|l}
\hline \multicolumn{1}{c|}{ MUNICÍPIO } & \multicolumn{1}{c}{ SETOR } & \multicolumn{1}{c}{ AFIRMAÇÃO } \\
\hline Capim Branco & Comércio & "Sempre estou ligado no que está acontecendo no Brasil e no mundo". \\
\hline Confins & Serviços & "Adoro escutar rádio enquanto estou trabalhando". \\
\hline Matozinhos & Comércio & $\begin{array}{l}\text { "Procuro saber sobre política e economia, porque tudo que acontece interfere } \\
\text { no negócio, que nem essa crise econômica!". }\end{array}$ \\
\hline Lagoa Santa & Serviços & "Acompanhamos tudo o que acontece pelo noticiário". \\
\hline Pedro Leopoldo & Comércio & "Assisto jornal na televisão, leio revistas e jornais". \\
\hline São José da Lapa & Serviços & "Quem está à frente do negócio precisa saber um pouco sobre economia". \\
\hline Vespasiano & Serviços & $\begin{array}{l}\text { "Estou ligado em tudo o que acontece no Brasil e no mundo, mas também } \\
\text { quero acompanhar as coisas daqui da região. Sempre que tem um evento, eu } \\
\text { vou". }\end{array}$ \\
\hline
\end{tabular}

Fonte: Dados da pesquisa (2016).

Percebe-se que poucos são os proprietários de MPE entrevistados que levam em consideração informações relacionadas ao meio ambiente local ou regional na definição de estratégias para seus negócios. Além de confirmarem as percepções já anteriormente destacadas de que tal público trabalha com informações mais operacionais e de curto prazo, e não com foco nas oportunidades e ameaças que podem impactar nas estratégias de longo prazo, quando o fazem neste sentido acabam considerando informações basicamente do macroambiente econômico, e não do contexto mais regional, onde de fato atuam e competem.

Também vale ressaltar que tais afirmações advindas das entrevistas realizadas, bem como da análise dos documentos que porventura representam os esforços dos proprietários das MPE em definirem um mínimo planejamento para suas empresas, confirmam e ratificam as observações já destacadas e apoiadas por Gimenez, Pelisson, Krüger e Hayashi Jr (1999) e de Alves, Antonialli, Lopes, Souki e Reis Neto (2013).

Sobre as respostas às questões "Quais são as ações/estratégias que sua empresa tem utilizado para conquistar clientes? E para manter os clientes atuais? E para enfrentar a concorrência? E para identificar oportunidades de crescimento?", tem-se que:

- Os gestores apontam que o atendimento personalizado, assim como a qualidade dos produtos e serviços, são os principais diferenciais das suas empresas, e que esses requisitos podem gerar novos clientes e superar a concorrência;

- No tocante à identificação de oportunidades de crescimento, a maioria dos gestores sequer têm respostas a esta questão, por não conseguirem enxergar as possibilidades de expansão dos negócios.

Percebe-se, na prática, que os proprietários das MPE entrevistados acreditam na forma como atendem seus clientes e atuam no mercado, mas não possuem subsídios concretos para avaliarem se, de fato, tais ações são diferenciais ou não, comparativamente ao que é feito por empresas concorrentes. Ou seja, na prática, as opiniões emitidas são pessoais e parciais, e não embasadas em informações imparciais que poderiam ser advindas das práticas de monitoramento e/ou IC, já abordadas anteriormente.

Sobre a identificação de oportunidades de crescimento, os próprios entrevistados explicitaram não terem resposta a esta questão, o que corrobora a análise anteriormente colocada de que o foco de atenção e atuação dos proprietários das MPE da Aerotrópole de Belo Horizonte se concentram no curto prazo, e em aspectos operacionais, e não no longo prazo e em questões de cunho mais estratégico para seus negócios. 
No tocante às questões "Qual(is) é(são) o(s) diferencial(is) que sua empresa possui, atualmente, para atuar no seu mercado? Essas ações/estratégias realizadas são acompanhadas por você/alguém da sua empresa? Como isso é feito? Quem faz esse acompanhamento?", verificou-se que:

- Os empresários afirmam saber, com clareza, quais são os diferenciais competitivos dos negócios deles. Atendimento personalizado e pagamento facilitado são os diferenciais citados em, praticamente, todos os negócios pesquisados;

- No setor do comércio verifica-se a presença significativa de crediário, justificada pela proximidade e confiança dos proprietários para com os clientes;

- Os gestores permanecem pelo menos um turno de trabalho (manhã ou tarde) no ambiente profissional e fazem questão de não só atender, mas também de conversar e agradar os consumidores e clientes;

- A maioria dos gestores acompanha as ações estratégicas de maneira informal, sem reuniões agendadas com os funcionários e sem o uso de indicadores formais, especialmente em função da proximidade com as pessoas centrais na empresa.

Corroborando, mais uma vez, as análises já apontadas, as estratégias mencionadas pelos entrevistados caracterizam ações de curto prazo e de cunho mais tático e operacional, e muito menos de cunho estratégico e de longo prazo. E os aspectos citados como diferenciais são, na realidade, aspectos mínimos necessários para a sobrevivência de qualquer organização no mercado atual. Pode-se inferir que a ausência de indicadores para avaliação do desempenho do negócio caracteriza a falta de gestão, não só estratégica, mas do próprio negócio.

\subsubsection{Identificação do nível de percepção das MPE sobre a Aerotrópole de Belo Horizonte}

Aos serem perguntados se já ouviram falar do conceito da Aerotrópole de Belo Horizonte:

- Mais de $60 \%$ dos entrevistados desconhecem o conceito;

- Poucos têm uma superficial compreensão, desconhecendo o tema em profundidade e não compreendendo a potencialidade deste 'novo contexto' e as novas possibilidades de negócio que podem ser geradas na região;

- Apenas 2 entrevistados conhecem o conceito e o contexto com maior profundidade, e pretendem mobilizar-se para aproveitar a potencialidade desse mercado.

A Tabela 4 apresenta uma síntese das afirmações dos respondentes sobre o nível de conhecimento/desconhecimento sobre o conceito da Aerotrópole de Belo Horizonte.

Tabela 4 - Síntese sobre o conceito da Aerotrópole de Belo Horizonte

\begin{tabular}{l|l|l}
\hline \multicolumn{1}{c|}{ MUNICÍPIO } & \multicolumn{1}{c|}{ SETOR } & \multicolumn{1}{c}{ AFIRMAÇÃO } \\
\hline Capim Branco & Comércio & "Não sei o que é isso!" \\
\hline Confins & Comércio & "Nunca ouvi falar." \\
\hline Matozinhos & Serviços & "Sei o que é, mas não sei muitos detalhes." \\
\hline Lagoa Santa & Comércio & "Já ouvi falar, mas não entendo muito sobre o assunto." \\
\hline Pedro Leopoldo & Comércio & "Sei o que é, mas não sei detalhes." \\
\hline São José da Lapa & Comércio & "Não sei." \\
\hline Vespasiano & Serviços & "Conheço o conceito e quero aproveitar a oportunidade." \\
\hline
\end{tabular}

Fonte: Dados da pesquisa (2016).

Os resultados apresentados refletem, na realidade, não somente a falta de conhecimento por parte dos proprietários das MPE entrevistados sobre o contexto da Aerotrópole de Belo Horizonte onde se localizam, como também a ausência de um acompanhamento minucioso do mercado regional. Tais afirmativas consolidam as análises realizadas nos itens 4.2.1 e 4.2.2. deste artigo.

\section{CONSIDERAÇÕES FINAIS}

A partir dos dados e informações apresentados e analisados, segue-se a argumentação conclusiva acerca dos objetivos propostos pelo trabalho, e as consequentes considerações finais sobre os principais achados.

O primeiro objetivo específico era identificar as práticas de monitoramento do ambiente/Inteligência Competitiva realizadas pelas MPE da Aerotrópole de 
Belo Horizonte. Este objetivo foi atingido, através da constatação de que o "Ciclo da Inteligência Competitiva" considerado neste trabalho, com suas fases/subprocessos, não é integralmente realizado nas MPE pesquisadas. As etapas de necessidade, planejamento, coleta e análise são executadas, mas de maneira informal, pelos próprios gestores, e as etapas de disseminação e avaliação não são realizadas, uma vez que as informações operacionais e estratégicas das organizações se concentram 'na mente' dos proprietários.

Tais constatações se refletem no segundo objetivo específico do trabalho, que era identificar como tais MPE planejam e implementam suas Estratégias Empresariais na Aerotrópole de Belo Horizonte. Este objetivo específico foi também alcançado no trabalho, sendo demonstrado que a falta de formalização do processo de monitoramento/IC acaba colocando a atividade de definição de Estratégias Empresariais em segundo plano na agenda de prioridades dos proprietários entrevistados, sendo estes, na maior parte do seu tempo, consumidos com demandas e ações de curto prazo e operacionais, e não de longo prazo e mais estratégicas. Portanto, verifica-se a falta de processos mais estruturados e antecipativos para elaboração de Estratégias Empresariais, sendo estas muito mais emergentes e baseadas nas características empreendedoras dos proprietários das MPE entrevistadas.

Por último, o terceiro objetivo específico, que era de identificar o nível de percepção das MPE pesquisadas sobre a Aerotrópole de Belo Horizonte, foi também atingido. Os resultados demonstraram a falta de conhecimento por parte dos proprietários das MPE entrevistados sobre o conceito e o contexto da Aerotrópole de Belo Horizonte onde se localizam, e a ausência de um acompanhamento minucioso do mercado regional. Dessa forma, a grande maioria dos entrevistados não consegue enxergar possibilidades de crescimento, mesmo estando situados na Aerotrópole de Belo Horizonte. Já investidores nacionais e até internacionais, estando a muitos quilômetros de distância da Aerotrópole de Belo Horizonte, já vislumbraram oportunidades de geração de negócios e, consequentemente, de receitas nessa região.

Diante do cumprimento dos objetivos específicos propostos, pode-se afirmar que o objetivo geral do trabalho, que era analisar como se configura a Inteligência Competitiva nas MPE da Aerotrópole de Belo Horizonte com vistas à elaboração de suas Estratégias Empresariais, foi devidamente cumprido. Portanto, a pesquisa confirma as contribuições teóricas e gerenciais inicialmente propostas: i) em termos teóricos, contribui com um estudo inédito ao analisar como se configura a IC nas MPE da Aerotrópole de Belo Horizonte com vistas à elaboração de suas Estratégias Empresariais; ii) em termos gerenciais, contribui para um melhor entendimento sobre a atual gestão das organizações de pequeno porte localizadas nesta área de influência do Aeroporto, contribuindo com reflexões e sugestões de melhorias não somente nas práticas de monitoramento do mercado e de IC, como também na sua contribuição para a elaboração de Estratégias Empresariais eficazes e eficientes.

Como limitações da pesquisa, destacam-se que: i) o estudo não foi desenvolvido com o setor primário (indústria) devido à resistência de gestores representantes deste tipo de empresa para a realização da pesquisa, o que acaba limitando os resultados obtidos e respectivas análises aos setores participantes (comércio e serviços); ii) o foco nas MPE, o número de entrevistados e a regionalidade destas, apesar de se constituírem no recorte propositalmente definido para a pesquisa, indicam que os resultados obtidos só podem ser representativos para este conjunto de empresas, e no contexto da Aerotrópole de Belo Horizonte, dificultando generalizações. Entretanto, vale ressaltar que a realização do processo de triangulação de fontes de coleta e análise dos dados permitiu contornar algumas destas limitações, aumentando a credibilidade das interpretações dos resultados obtidos.

Por último, o presente trabalho, a partir da diversidade dos resultados alcançados (mesmo considerando as limitações expostas), pode servir como fonte de consulta para pesquisas futuras sobre a Aerotrópole de Belo Horizonte, necessárias nos próximos anos em função da transformação do mercado, da economia, dos hábitos e da maneira de viver na região. Resguardadas as prováveis diferenças, a utilização dos procedimentos metodológicos adotados, e até mesmo do referencial teórico e dos resultados obtidos, podem ser utilizados como parâmetro para novos estudos e respectivas análises sobre Aerotrópoles de outras regiões, com o foco para a percepção dos gestores das empresas constituintes sobre a adoção de práticas de IC alinhadas aos processos de definição de Estratégias Empresariais.

\section{REFERÊNCIAS}

Albano, C. S., \& Araújo, M. H. (2013, maio). Inteligência competitiva e monitoramento ambiental utilizando informações disponíveis na internet: a viabilidade de utilizar dados governamentais abertos. In: EnADI - Encontro de Administração da Informação. Anais eletrônico... Bento Gonçalves, RS, Brasil, 4.

Alves, R. C., Antonialli, L. M., Lopes, H. E. G., Souki, G. Q., \& Reis Neto, M. T. (2013). Estratégias construídas nas micro e pequenas empresas: um estudo no mercado central de Belo Horizonte. Revista da Micro e Pequena Empresa, 7(3), 3-18.

Amaral, R. M., Garcia, L. G., \& Alliprandini, D. H. (2008). Mapeamento e gestão de competências em 
inteligência competitiva. DataGramaZero - Revista de Ciência da Informação, 9(6), 7-19.

Ansoff, H. I., \& McDonnell, E. J. (1993). A administração estratégica (2a ed.). São Paulo: Atlas.

Baierle, I. C., Frozza, R., Nara, E. O. B., \& Kipper, L. M. (2011). O Ciclo da Produção de Inteligência como apoio à estratégia de tomada de decisão organizacional. Revista Produção Online, 11(4), 1086-1113.

Barbalho, C. R. S., Valentim, M. L. P., \& Hoffmann, W. A. M. (2007, outubro). Uso da inteligência competitiva em empresas brasileiras de produtos naturais. In: ENANCIB - Encontro Nacional de Pesquisa e Pós-Graduação em Ciência da Informação. Anais eletrônico... Salvador, BA, Brasil, 8 .

Barbosa, R. (2006). Uso de fontes de informação para a inteligência competitiva: um estudo da influência do porte das empresas sobre o comportamento informacional. Encontros Bibli: revista eletrônica de biblioteconomia e ciência da informação, 11(1), 91-102.

Barbosa, R. R. (2008). Gestão da Informação e do Conhecimento: origens, polêmicas e perspectivas. Informação \& Informação, Londrina, 13(Edição Especial), 1-25.

Bardin, L. (2011). Análise de Conteúdo. Edição Revisada e Ampliada. Brasil: Edições 70 Brasil.

Barney, J. B., \& Hesterly, W. S. (2007). Administração estratégica e vantagem competitiva. São Paulo: Pearson Prentice Hall.

Belissa, T. (2016). Vespasiano terá complexo imobiliário de R\$ 1,5 bilhão. Diário do Comércio, Caderno Negócios. Recuperado em 10 maio 2016, de

http://diariodocomercio.com.br/noticia.php?tit=ves pasiano_tera_complexo_imobiliario_de_r_1,5_bilh ao\&id $=168752$

Benbasat, I., Goldstein, D. K., \& Mead, M. (1987). The Case Research Strategy in Studies of Information Systems. MIS Quarterly, 11(3), 369-386.

Bortoluzzi, F. R., da Silva, E. R., Saciloto, E. B., \& Fachinelli, A.C. (2014). Inteligência Estratégica e Análise: revisão sistemática da literatura. Revista Inteligência Competitiva, 4(3), 27-38.

Bressan, F. (2000). O Método do Estudo de Caso. Administração On Line, 1(1), jan./mar.
Calof, J. L., \& Wright, S. (2008). Competitive intelligence: A practitioner, academic and interdisciplinary perspective. European Journal of Marketing, 42(7/8), 717-730.

Choo, C.W. (2006). The knowing organization: how organizations use information to construct meaning, create knowledge, and make decisions. $2^{\mathrm{a}}$ Ed. New York: Oxford University Press.

Collis, J., \& Hussey, R. (2005). Pesquisa em administração: um guia prático para alunos de graduação e pós graduação. $2^{\mathrm{a}}$ ed. Porto Alegre: Bookman.

Coutinho, M. L. G., \& Ramos, H. R. (2015). Monitoramento Ambiental em empresa de pequeno porte: caso Run\&Fun Assessoria Esportiva. In: IV SINGEP - Simpósio Internacional de Gestão de Projetos, Inovação e Sustentabilidade. Anais Eletrônico... São Paulo: UNINOVE.

Creswell, J. W. (1994). Research design: qualitative, quantitative, and mixed methods approaches (2a ed.). Thousand Oaks: Sage.

Davenport, T. H., \& Prusak, L. (1998). Conhecimento empresarial. Rio de Janeiro: Campus.

Figueiredo, N. M. A. (2007). Método e metodologia na pesquisa científica. $2^{\mathrm{a}}$ ed. São Caetano do Sul, São Paulo, Yendis Editora.

Gil, A. C. (2002). Como elaborar projetos de pesquisa. 4. ed. São Paulo: Atlas.

Gimenez, A. P., Pelisson, C., Krüger, E. G. S., \& Hayashi Jr, P. (1999). Estratégia em pequenas empresas: uma aplicação do modelo de Miles e Snow. Revista de Administração Contemporânea, 3(2), 53-74.

Harrison, J. S. (2002). Administração Estratégica de recursos e relacionamentos. Porto Alegre: Bookman.

Herring, J. P. (1999). Key Intelligence Topics: A Process to Identify and Define Intelligence Needs. Competitive Intelligence Review, 10(2), 4-14.

Hoffmann, W. A. M. (2011). Monitoramento da informação e inteligência competitiva: realidade organizacional. Revista de Ciência da Informação e Documentação, 2(2), 125-144.

Hoffmann, W.A.M., \& Chemalle, K.E. (2006). Gestão da informação para integrar inteligência competitiva em micro e pequena empresas de arranjos produtivos locais. In: GeCIC - Congresso 
Ibero Americano de Gestão do Conhecimento e Inteligência Competitiva. Anais eletrônico... Curitiba, PR, Brasil.

Kanter, R. M. (1995). Thriving Locally in the Global Economy. Harvard Business Review, 151-158.

Kasarda, J., \& Lindsay, G. (2012). Aerotrópole: o modo como viveremos no futuro. São Paulo: DVS Editora.

Leone, R. J. G., \& Leone, N. M. C. P. G. (2012). Pequenas e médias empresas: contribuições para a discussão sobre por que e como medir o seu tamanho. RAUnP. Ano IV (1), out.2011/mar.2012.

Maciel, D. (2014). Belo Horizonte no foco do mundo. Diário do Comércio, Caderno Negócios. Recuperado em 10 maio 2016, de http://www.diariodocomercio.com.br/noticia.php?id $=138459$.

Mafra Pereira, F. C. (2008) Uso de fontes de informação por consultores empresariais: um estudo junto ao mercado de consultoria de Belo Horizonte. Perspectivas em Ciência da Informação, 13(1), 95-111, jan./abr.

Mafra Pereira, F. C. (2016). Fontes de Informação para Negócios: análise sobre frequência, relevância e confiabilidade, baseada em estudo empírico com empresários e gestores organizacionais. Perspectivas em Ciência da Informação, 21(2), 100-119, abr./jun.

Mafra Pereira, F. C., \& Santos, M.G. do A. (2015). Inteligência Competitiva na Indústria Alimentícia: práticas adotadas e proposta de estruturação da IC em uma empresa de processamento mínimo de frutas e hortaliças de Minas Gerais. Revista Inteligência Competitiva, 5(4), 1-28.

Mafra Pereira, F. C., Borges, M. A., \& Jordão, R. V. D. (2015). Inteligência Competitiva em Redes Interorganizacionais: proposta de modelo para Centrais de Negócios. In: XVI ENANCIB Encontro Nacional de Pesquisa em Ciência da Informação. Anais Eletrônico... João Pessoa: UFPB.

Mafra Pereira, F. C., Carvalho, R. B. de, \& Jordão, R. V. D. (2016). Análise do Ciclo de Inteligência Competitiva em Arranjos Produtivos Locais: estruturação e implantação do bureau de inteligência do APL de software de Belo Horizonte. Revista Inteligência Competitiva, 6(1), 139-164.

Mafra Pereira, F.C., Carvalho, R. B., Neves, J. T. R., \& Quintão, A. A. (2017). Uso da Inteligência
Competitiva por Micro, Pequenas e Médias Empresas: um estudo de caso nas empresas associadas à ACITA, Itabira, Minas Gerais, Brasil. In: XVIII ENANCIB - Encontro Nacional de Pesquisa em Ciência da Informação. Anais Eletrônico... Marília: UNESP.

Mafra Pereira, F.C.; \& Barbosa, R.R. (2009). A decisão estratégica por executivos de micro e pequenas empresas e a cadeia alimentar informacional como modelo integrativo de fontes de informação. In: Anais do Encontro Nacional de Pesquisa em Ciência da Informação, X ENANCIB, João Pessoa: UFPB, 1113-1131.

Malhotra, N. K. (2006). Pesquisa de Marketing: uma orientação aplicada. $3^{\mathrm{a}}$ ed. Porto Alegre: Bookman.

Martins, E. L. C. (2011). Monitoramento informacional do ambiente de negócios na micro e pequena empresa (MPE): estudo do comércio varejista de materiais para a construção de Cuiabá-MT. Tese de Doutorado, Universidade de Brasília, Brasília, DF, Brasil.

Martre, H. (1994). Intelligence économique et stratégie des enterprises. Paris: Commissariat général du Plan.

Mattar, F.N. (1996). Pesquisa de Marketing. São Paulo: Atlas.

Mazzotti, A.A., \& Gewandsznajder, F. (1999). $O$ método nas ciências naturais e sociais: pesquisa quantitativa e qualitativa. São Paulo: Pioneira.

Miller, J. (2002). O Milênio da inteligência competitiva. Porto Alegre: Bookman.

Mintzberg, H. (1987). Crafting strategy. Harvard Business Review, 65(4), 66-75.

Mintzberg, H. (2007). Ascensão e queda do Planejamento Estratégico. Porto Alegre: Bookman.

Moraes, C. R. B., \& Fadel, B. (2008). Triangulação metodológica para o estudo da gestão da informação e do conhecimento em organizações. In M. L. P. Valentin (Org.). Gestão da informação e do conhecimento. (pp. 27-40). São Paulo: Polis.

Nonaka, I., \& Takeuchi, H. (1997). Criação de conhecimento na empresa: como as empresas japonesas geram a dinâmica da inovação. Rio de Janeiro: Campus.

Oliveira, A. A. D. (2010). Observação e entrevista em pesquisa qualitativa. Revista FACEVV, 4, 22-27. 
Oliveira, P. H. de, \& Sade, W. (2016). Inteligência Competitiva no contexto das empresas mineiras de artefatos de estanho. Perspectivas em Ciência da Informação, 21(1), 23-41, jan./mar.

Oliveira, P. H. de, \& Teles, E. L. (2015). Relações de dependência informacional entre os processos de administração estratégica e de inteligência competitiva. Revista Inteligência Competitiva, 5(2), 17-39, abr./jun.

Pacheco, C. G. (2010). Prospecção e Monitoramento informacional no contexto da inteligência competitiva em microempresas do ramo óptico da região de Marília/SP. Dissertação de Mestrado, Universidade Estadual Paulista, Marília, SP, Brasil.

Pearce II, J. A., Chapman, B. L., \& David, F. R. (1982). Environmental scanning for small and growing firms. Journal of Small Business Management, 20(3), 27-34.

Pereira, C. E., \& Perez, G. (2015). A Captura de Sinais do Ambiente Externo como elemento para o Processo de Inovação em Micro e Pequenas Empresas. In: IV SINGEP - Simpósio Internacional de Gestão de Projetos, Inovação e Sustentabilidade. Anais Eletrônico... São Paulo: UNINOVE.

Porter, M. E. (1996). Estratégia competitiva: técnicas para análise de indústrias e da concorrência (7a ed.). Rio de Janeiro: Campus.

Rocha Júnior, E. de A., Guimarães, E. H. R., \& Jeunon, E. E. (2014). Gestão do Conhecimento em Agência de Fomento à Pesquisa: Proposição de um Modelo Aplicado. Revista Gestão \& Tecnologia,14(3), 244260.

Roesch, S. M. A. (2009). Projetos de estágio e de pesquisa em administração. $3^{\text {a }}$ ed. São Paulo: Atlas.

Sanday, P. R. (1984). The ethnographic paradigma. In: Van Haanen, J. (ed.) Qualitative methodology. Bervely Hills, Sage Publ..
SEBRAE. Serviço Brasileiro de Apoio às Micro e Pequenas Empresas. (2014). Pesquisa de avaliação 2013 e perspectivas 2014 das micro e pequenas empresas de Minas Gerais. Belo Horizonte: SEBRAE.

Souza, E. D. de., Dias, E. J. W., \& Nassif, M. E. (2011). A Gestão da Informação e do Conhecimento na Ciência da Informação: perspectivas teóricas e práticas organizacionais. Informação \& Sociedade: Estudos, 21, 55-70.

Starec, C. (2012). Gestão da Informação, Inovação e Inteligência Competitiva: como transformar a informação em vantagem competitiva nas organizações. São Paulo: Saraiva.

Teixeira, T. M. C., \& Valentim, M. L. P. (2016). Inteligência Competitiva Organizacional: um estudo teórico. Perspectivas em Gestão \& Conhecimento, 6(Número Especial), 3-15, jan.

Tjora, A. H. (2006). Writing small discoveries: an exploration of fresh observers' observations. Qualitative Research, 6(4), 429-451.

Triviños, A.N.S. (1987). Introdução à pesquisa em ciências sociais. São Paulo. Atlas.

Vergara, S. C. (2014). Projetos e Relatórios de Pesquisa em Administração. $15^{\mathrm{a}}$ ed. São Paulo: Atlas.

Vitorino, A. H., \& Garcia, L. G. (2013). Inteligência Competitiva na ampliação da efetividade da publicidade de Micro e Pequenas Empresas. In: XIV ENANCIB - Encontro Nacional de Pesquisa em Ciência da Informação. Anais Eletrônico... Florianópolis: UFSC.

Yin, R. K. (1984). Case study research: design and methods. Beverly Hills, CA: Sage Publishing. 